Original Article

\title{
EFFECTIVENESS OF ANTENATAL CARE PACKAGE ON KNOWLEDGE OF PREGNANCY INDUCED HYPERTENSION FOR ANTENATAL MOTHERS IN SELECTED HOSPITALS OF MANGALORE
}

\author{
Sr. Jolly Joseph ${ }^{1}$, Sabitha Nayak', Philomena Fernandes ${ }^{3} \&$ Vandana Suvarna ${ }^{4}$ \\ ${ }^{1}$ Senior Lecturer, St. Thomas College of Nursing, Changanacherry, Kottayam. \\ ${ }^{2}$ Vice Principal, ${ }^{3} \mathrm{HOD}$, Department of OBG Nursing, Nitte Usha Institute of Nursing Sciences, Nitte University, \\ Mangalore - 575 018, India \\ ${ }^{4}$ Lecturer, Department of Statistics, Yenepoya University, M angalore - 575 018, India. \\ Correspondence: \\ Sabitha Nayak \\ Vice Principal, Nitte Usha Institute of Nursing Sciences, Nitte University, Mangalore - 575 018, India \\ E-mail: sabitha_nayak@yahoo.ie Mobile : +91 9448842698
}

\begin{abstract}
:
The study was conducted on effectiveness of antenatal care package on knowledge of pregnancy induced hypertension for antenatal mothers from 7/09/2009 to 10/10/2009. The research design was an evaluative approach using one group pretest post test the experimental design 40 antenatal mothers were selected by purposive sampling. Data was collected using structured knowledge questionnaire. Antenatal care package was developed.

The pre test knowledge questionnaire was administered on the first day followed by an antenatal care package. The post test was conducted after five days using the same tool. The pretest knowledge data showed that maximum number of mothers $26(65.5 \%)$ scored between the range of $11-20 \%$ (average).The mean knowledge score was 14.88 where as the maximum possible score was 30.Among seven areas, the mean percentage knowledge in the area of basic factors of PIH was $43.75 \%$, clinical features $41 \%$, diagnosis $44 \%$, management $57.5 \%$,diet $50 \%$,complication $50 \%$,and prevention $58 \%$.

The ' $t$ " value showed the significant difference in the posttest, (' $t$ ' calculated value of pretest and post test knowledge scores $=14.22$ $p \varangle 0.05$ which showed that antenatal care package was effective in improving the knowledge of antenatal mothers on pregnancy induced hypertension.

There was significant association between pretest level of knowledge and age, educational status, occupation, monthly income, parity, gestational age, history of hypertension in previous pregnancy.
\end{abstract}

Keywords: pregnancy induced hypertension, antenatal mothers, antenatal care package

\section{Introduction :}

Pregnancy is a kind of miracle by the God and a mother's joy begins when new life is stirring inside and a tiny heartbeat is heard for the very first time. Pregnancy is a unique and exciting time in a woman's life, as it highlights the woman's amazing creative and nurturing powers while

\begin{tabular}{|c|}
\hline Access this article online \\
\hline Quick Response Code \\
\hline
\end{tabular}
providing a bridge to the future.

Hypertensive disorders in pregnancy are among the major causes of maternal and perinatal mortality and morbidity. It is one of the commonest medical disorders diagnosed by obstetricians in clinical practice. Approximately $1,00,000$ women die worldwide per annum because of pregnancy induced hypertension .It is said that preeclampsia and eclampsia contribute to death of a woman every 3 minutes worldwide. The global maternal mortality rate is estimated to be 400 per 1,00,000 live births due to pregnancy or childbirth (Stevens 2000) Birkhead, Callister and Vega quote "It's just my way of thinking that pregnant women have one foot in life and one foot in death. And that's why if you don't care for yourself, you can die". The most common causes of maternal death worldwide are hemorrhage, infection, unsafe abortion, pregnancy induced hypertension and obstructed labor. It is estimated that 
approximately $25 \%$ of maternal deaths are caused by hemorrhage, $15 \%$ by infections, $13 \%$ by unsafe abortion ,12\% by pregnancy induced hypertension , $8 \%$ by obstructed labor and $8 \%$ by other direct causes and $20 \%$ are due to indirect causes including malaria, heart disease and iron deficiency anemia. ${ }^{1}$

\section{Statement of The Problem :}

"Effectiveness of antenatal care package on knowledge of pregnancy induced hypertension for antenatal mothers in selected hospitals, Mangalore."

\section{Objectives of The Study:}

I To determine the existing knowledge of antenatal mothers regarding pregnancy induced hypertension using a structured knowledge questionnaire.

I To evaluate the effectiveness of antenatal care package on pregnancy induced hypertension in terms of gain in knowledge scores.

I To find an association between pretest knowledge scores on pregnancy induced hypertension with selected demographic variables.

\section{Background of The Study:}

Pregnancy is a unique and existing time in a woman's life, as it highlights the woman's amazing creative and nurturing powers while providing a bridge to the future. Pregnancy induced hypertension remains one of the three leading causes of maternal mortality and if it occurs along with proteinuria. It occurs in $5 \%$ to $7 \%$ of all pregnancies. Pregnancy should be a wonderful time, but it can be worrying too. Some of the women are unfortunate to have problems related to pregnancy and child birth. So mothers should improve their knowledge to reduce the maternal mortality rate due to pregnancy induced hypertension.

\section{Conceptual Framework:}

The framework of the study is based on general system theory model developed by Ludwig Von Bretalanffy (1986).General system theory serves as a model for viewing people as interacting components within a boundary that filters the type and rate of exchange with the environment. A system consists of both structural and functional components. A structure refers to the arrangement of the facts at a given time. Function is the process of continuous change in the system as a matter; energy and information are exchanged with the environment. The client is an open system capable of both input and output related to the environmental influences, interacting with the environment by adjusting the environment to itself. The feed back information of environment in response to the system's output is used by the system in adjustment, correlation and accommodation to the interaction with the environment.

\section{Review of Literature :}

A case control study was conducted in a tertiary hospital in Nigeria on 1803 women to determine the risk factors for pregnancy induced hypertension (PIH). Multiple logistic regression analysis was used to determine the risk factors for preeclampsia. Results showed that one hundred and thirty seven $(7.6 \%)$ of the 1803 women who delivered during the period had pre-eclampsia /eclampsia of these 128 (93.4\%) were analyzed; ninety one (71.1\%) women were primigravida. ${ }^{2}$

A qualitative exploratory study was conducted in North America on 24 women by convenience sampling to explain he effectiveness of bed rest for reducing the edema in pregnancy induced hypertension. The result says that $10 \%$ reduction in edema was found over a 4 week period rest. The study shows that mothers with PIH had reduced their edema after taking bed rest either at home or at hospital. ${ }^{3}$

A randomized control study was conducted in South Africa on 15528 women to assess the calcium supplementation will reduce the risk of hypertensive disorders. The results shows that High blood pressure was reduced with calcium supplementation rather than placebo in 14,946 women $(95 \%)$.The study conclude that calcium supplementation appears to reduce the risk of preeclampsia and to reduce the rare occurrence of the composite outcome ' maternal death and serious morbidity". ${ }^{4}$

\section{Methodology:}

One group pre test post test design which is a pre 
experimental research design was adopted.

\section{Sample :}

40 mothers admitted with pregnancy induced hypertension at selected hospitals in Mangalore and who satisfied the inclusion criteria were included as samples.

\section{Data Collection Process :}

Pre-test was administered to the participants who were admitted with pregnancy induced hypertension using structured knowledge questionnaire. The researcher collected the demographic data along with this. It took approximately 30 minutes. After pre test researcher distributed the antenatal care package on pregnancy induced hypertension to the participants. After 5 days of intervention, the investigator administered the post test to assess the level of knowledge of mothers using the same structured knowledge questionnaire.

\section{Results:}

The data was analyzed based on objectives and hypothesis. Both descriptive and inferential statistics was used for data analysis. Descriptive statistics used were frequency, percentage with tabular presentation. The paired 't' test was used to test the significance of difference in the mean pretest and posttest knowledge and practice scores. The study revealed that most of the mothers $19(47.5 \%)$ were within in the age group of 20-25 yrs,most of the mothers

\section{References:}

1. Birkhead A, Callister LC, Vega R .Global maternal mortality . M aternity and child health Nursing Journal.2005 M arch; 30(3):185-192.

2. Anorlu RI, Iwuala NC, Odum CU.Risk factors for preeclampsia in Lagos Nigeria.J obstetric and gynecology M ay 2005;45(4):278-282.

3. Adler $\mathrm{CL}$, Zarchin YR.The pregnant women on home or hospital bed rest. J Obstet Gynecol 2002M ar; 31(4):418-427.

4. Hofmeyr GJ, Duley L, Tallch A .Dietary calcium supplementation for prevention of pregnancy induced hypertension and related problems. Int J Gynaecol Obstet. 2007Aug; 114(8):933-943.
14(35\%) had PUC level education, more than half of mothers, $23(57.5 \%)$ were house wives, majority $14(35 \%)$ of the mothers had monthly income between Rs 4001-5000, more than half of the mothers $22(55 \%)$ were primigravida, majority of the mothers $18(45 \%)$ were of the gestational age between 25-29 weeks, most of the mothers 29 (72.5\%) had absence of history of PIH in previous pregnancy.

The pretest knowledge data showed that maximum number of mothers $26(65.5 \%)$ scored between the range of $11-20 \%$ (average).The mean knowledge score was 14.88 where as the maximum possible score was 30 .Among seven areas, the mean percentage knowledge in the area of basic factors of $\mathrm{PIH}$ was $43.75 \%$, clinical features $41 \%$, diagnosis $44 \%$, management $57.5 \%$, diet $50 \%$,complication $50 \%$,and prevention $58 \%$.

The ' $t$ " value showed the significant difference in the posttest, ('t' calculated value of pretest and post test knowledge scores $=14.22 \quad p \varangle 0.05$ which showed that antenatal care package was effective in improving the knowledge of antenatal mothers on pregnancy induced hypertension.

There was significant association between pretest level of knowledge and age, educational status, occupation, monthly income, parity, gestational age, history of hypertension in previous pregnancy. 